\title{
Olanzapine Versus Risperidone in Children and Adolescents with Psychosis: A Meta-Analysis of Randomized Controlled Trials
}

\author{
Lei Xia, MD, ${ }^{1,2}$ Wen-Zheng Li, MD, ${ }^{2}$ Huan-Zhong Liu, MD, PHD, ,2, \\ Rui Hao, MD, ${ }^{1,2}$ and Xiang-Yang Zhang, MD, $\mathrm{PHD}^{1-3}$
}

\begin{abstract}
Objective: To compare the efficacy and safety of olanzapine and risperidone in children and adolescents (aged $\leq 18$ years) with psychosis by conducting a meta-analysis of randomized controlled trials (RCTs).

Methods: Several English and Chinese databases were searched for studies published before February 8th, 2017. Two independent investigators screened the studies according to prespecified criteria and extracted the data. Review Manager 5.3 was used to conduct the data synthesis.

Results: Eight RCTs involving 457 participants (225 participants in the olanzapine group and 232 participants in the risperidone group) were included. No significant differences were observed in the mean scores on the Positive and Negative Syndrome Scale/Brief Psychiatric Rating Scale (standard mean difference [SMD] $=-0.06,95 \%$ confidence intervals $[\mathrm{CI}]=[-0.31,0.19], p=0.63)$, the positive symptom scores $(\mathrm{SMD}=-0.09,95 \% \mathrm{CI}=[-0.32,0.15], p=0.48)$, or the negative symptom scores $(\mathrm{SMD}=-0.1195 \% \mathrm{CI}=[-0.34,0.13], p=0.38)$ between the two groups. Regarding adverse effects, the mean increases in weight $(\mathrm{MD}=2.90,95 \% \mathrm{CI}=[1.41,4.39], p=0.0001)$, body mass index $(\mathrm{MD}=0.90,95 \% \mathrm{CI}=[0.42$, 1.38], $p=0.0003$ ), and incidence of hypersomnia (risk ratios $[\mathrm{RR}]=1.98,95 \% \mathrm{CI}=[1.15,3.43], p=0.01$ ) were higher in the olanzapine group, while the incidence of insomnia $(\mathrm{RR}=0.31,95 \% \mathrm{CI}=[0.11,0.85], p=0.02)$, prolactin elevation $(\mathrm{RR}=0.11,95 \% \mathrm{CI}=[0.01,0.85], p=0.03)$, myotonia $(\mathrm{RR}=0.12,95 \% \mathrm{CI}=[0.03,0.49], p=0.003)$, tremor $(\mathrm{RR}=0.22,95 \%$ $\mathrm{CI}=[0.08,0.63], p=0.005)$, and akathisia $(\mathrm{RR}=0.27,95 \% \mathrm{CI}=[0.12,0.57], p=0.0007)$ was higher in the risperidone group. Conclusions: There is no significant difference in efficacy between olanzapine and risperidone for the treatment of children and adolescents with psychosis, but the side effect profiles of these two medications differ. High-quality RCTs are needed before recommending clinical treatment in children and adolescents.
\end{abstract}

Keywords: olanzapine, risperidone, antipsychotics, children and adolescents, meta-analysis

\section{Introduction}

$\mathbf{S}^{\mathrm{c}}$ CHIZOPHRENIA AND OTHER psychoses often present in childhood and adolescence with consequent impairments in psychosocial functioning and quality of life. Early-onset psychosis (EOP, age of onset before 18 years) is considered a more severe disorder than adult-onset psychosis and is accompanied by a higher level of negative and nonspecific symptoms (García et al. 2013). Patients with EOP have a poor prognosis, severe depressive symptoms, and a high death rate (Ropcke and Eggers 2005; Remschmidt et al. 2007). More safe and effective treatments are needed for these vulnerable youths.

Antipsychotic medication is the mainstay for the clinical treatment of mental diseases and functions differently in youths and adults. Weight gain and metabolic disturbances are more likely to occur in children and adolescents than in adults who take antipsychotic drugs (Arango et al. 2016; Baeza et al. 2017). The use of antipsychotics in children and adolescents has been controversial. In Europe and the United States, the clinical trials are expensive.

\footnotetext{
${ }^{1}$ Department of Psychiatry, Chaohu Hospital of Anhui Medical University, Hefei, China.

${ }^{2}$ Department of Psychiatry, Anhui Psychiatric Center, Anhui Medical University, Hefei, China.

${ }^{3}$ Department of Psychiatry and Behavioral Sciences, The University of Texas Health Science Center at Houston, Houston, Texas.

Funding: This study was funded by the open project foundation of the Collaborative Innovation Center for Neuropsychiatric Diseases and Mental Health in Anhui Medical University: Neuropsychological Study of Childhood Schizophrenia (Code: NDMHCI-16-02).

(C) Lei Xia et al. 2018; Published by Mary Ann Liebert, Inc. This article is available under the Creative Commons License CC-BY-NC (http:// creativecommons.org/licenses/by-nc/4.0). This license permits non-commercial use, distribution and reproduction in any medium, provided the original work is properly cited. Permission only needs to be obtained for commercial use and can be done via RightsLink.
} 
Many ethical restrictions and no clear financial incentive to perform pediatric efficacy or safety trials support have resulted in a lack of relevant clinical trials. In the United States, only five new antipsychotics (i.e., aripiprazole, olanzapine, paliperidone, quetiapine, and risperidone) have been approved by the American Food and Drug Administration for the treatment of schizophrenia in children and adolescents. Second-generation antipsychotics (SGAs) are preferred over first-generation antipsychotics for the treatment of children and adolescents due to their typical lower rates of extrapyramidal symptoms (EPS) and tardive dyskinesia (Correll et al. 2006; Correll and Kane 2007). Previous knowledge regarding SGAs was largely obtained from studies involving adults with psychosis. Clinical trials, particularly active-controlled trials involving children and adolescents with psychosis, have been limited, and their sample sizes have been small. It turns out that active-control trials with large samples in pediatric patients do exist, but they are usually industry sponsored or drug companies tend not to publish unless their drug does better.

Olanzapine and risperidone, which are the two most commonly used SGAs, play important roles in the treatment of children and adolescents with psychosis. A systematic review and meta-analysis (Kumar et al. 2013) of studies obtained from the Cochrane Library compared olanzapine with risperidone in youth, but included only 2 randomized controlled trials (RCTs) with merely 111 participants. Furthermore, few RCTs have been included in other relevant reviews or meta-analyses (Seida et al. 2012; Harvey et al. 2016), and all have been obtained from English-language databases. According to a 5-year survey (Yan and Cui 2016), olanzapine has been used most frequently $(24.6 \%)$ in China to treat children and ado- lescents with schizophrenia, followed by risperidone (21.9\%). Thus, we conducted this meta-analysis of RCTs obtained from both English and Chinese language databases to compare the efficacy and safety of olanzapine and risperidone for the treatment of children and adolescents with psychosis.

\section{Methods}

\section{Search strategy and selection criteria}

We systematically searched English (i.e., PubMed, Embase, and the Cochrane Library) and Chinese (i.e., VIP service platform, Chinese Biomedical Literature Service System [CBM], Chinese National Knowledge Infrastructure [CNKI], and WANFANG DATA) databases for RCTs that compared the efficacy and safety of olanzapine and risperidone in the treatment of children and adolescents with psychosis and were published before February 8, 2017 using the following terms and combinations of Chinese equivalent words: "olanzapine" AND "risperidone" AND ("children" OR "adolescent") AND ("schizophrenia" OR "psychosis" OR "schizophrenia spectrum and other psychotic disorders"). To avoid omissions, we inspected the references of all identified studies to identify additional relevant studies.

According to the principle of PICOS in evidence-based medicine, studies were included if they met the following criteria: Participants: all subjects aged $\leq 18$ years with a diagnosis of a schizophrenia spectrum or other psychotic disorder; Intervention and Comparison: olanzapine and risperidone; Outcomes: efficacy and safety; and Study design: only RCTs. The following studies and

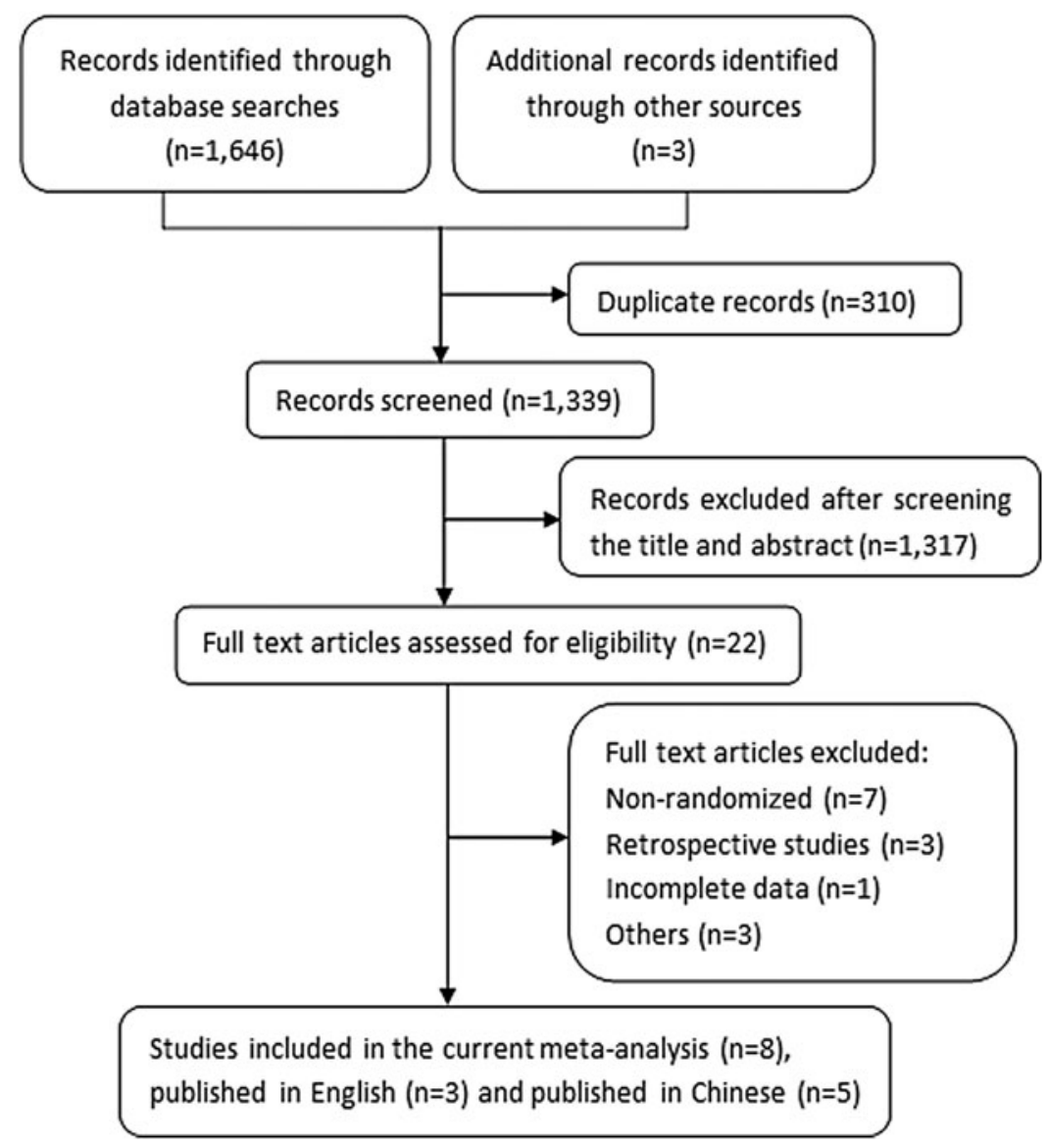

FIG. 1. Flowchart of study selection. 


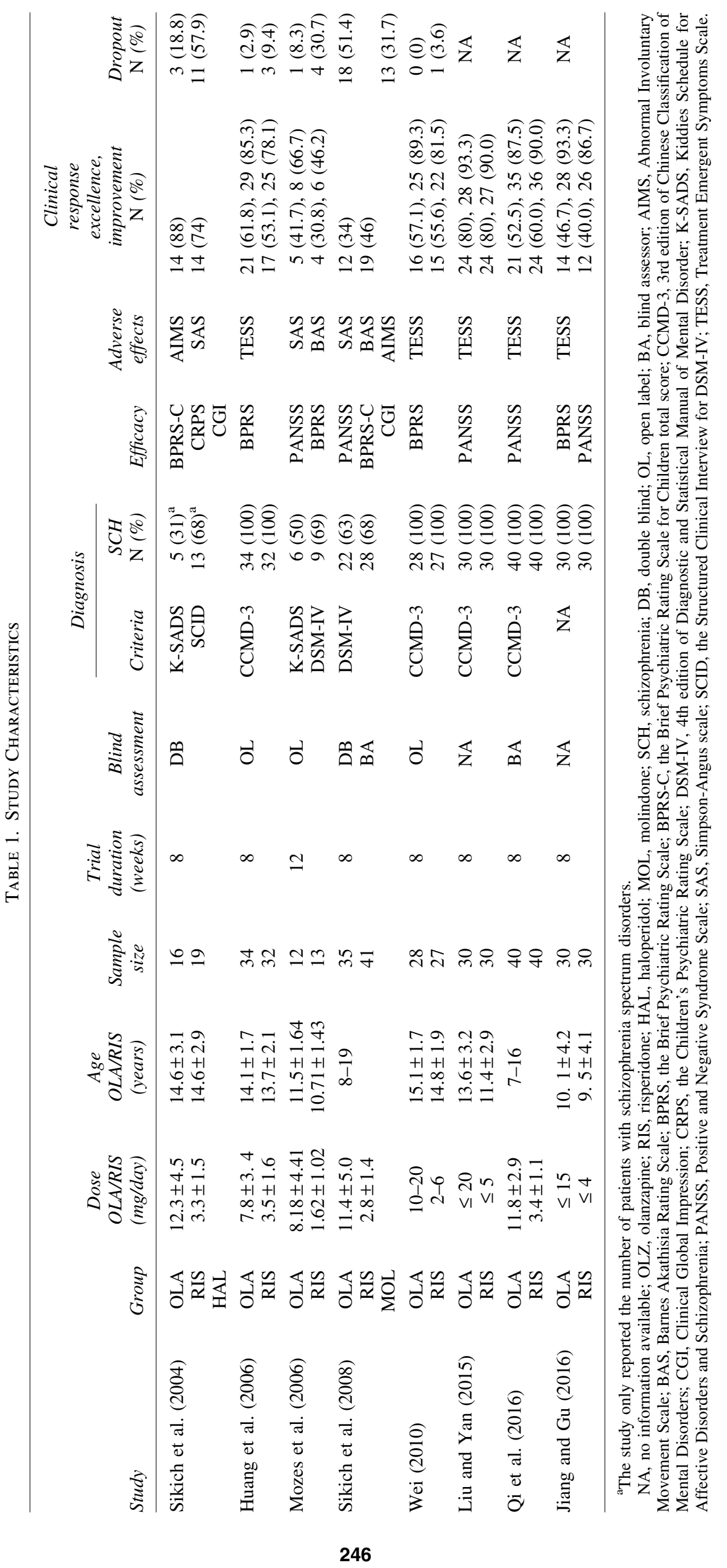


TABle 2. Risk of Bias AND JADAD SCORES

\begin{tabular}{|c|c|c|c|c|c|c|c|c|}
\hline Study & $\begin{array}{l}\text { Random } \\
\text { sequence } \\
\text { generation }\end{array}$ & $\begin{array}{c}\text { Allocation } \\
\text { concealment }\end{array}$ & $\begin{array}{c}\text { Blinding of } \\
\text { participants } \\
\text { and personnel }\end{array}$ & $\begin{array}{c}\text { Blinding of } \\
\text { outcome } \\
\text { assessment }\end{array}$ & $\begin{array}{l}\text { Incomplete } \\
\text { outcome } \\
\text { data }\end{array}$ & $\begin{array}{l}\text { Selective } \\
\text { reporting }\end{array}$ & $\begin{array}{l}\text { Other } \\
\text { biases }\end{array}$ & $\begin{array}{l}\text { Jadad } \\
\text { score }\end{array}$ \\
\hline Sikich et al. (2004) & $\mathrm{L}$ & NA & $\mathrm{L}$ & NA & $\mathrm{H}$ & NA & NA & 5 \\
\hline Huang et al. (2006) & NA & NA & $\mathrm{H}$ & NA & $\mathrm{L}$ & NA & NA & 2 \\
\hline Mozes et al. (2006) & NA & NA & $\mathrm{H}$ & NA & $\mathrm{H}$ & NA & NA & 2 \\
\hline Sikich et al. (2008) & NA & $\mathrm{L}$ & $\mathrm{L}$ & $\mathrm{L}$ & $\mathrm{H}$ & $\mathrm{L}$ & NA & 6 \\
\hline Wei (2010) & NA & NA & $\mathrm{H}$ & NA & $\mathrm{L}$ & NA & NA & 2 \\
\hline Liu and Yan (2015) & $\mathrm{L}$ & NA & NA & NA & NA & NA & NA & 3 \\
\hline Qi et al. (2016) & NA & NA & NA & $\mathrm{L}$ & NA & NA & NA & 2 \\
\hline Jiang and Gu (2016) & NA & NA & NA & NA & NA & NA & NA & 1 \\
\hline
\end{tabular}

NA, no information available; $\mathrm{L}$, low risk; $\mathrm{H}$, high risk.

articles were excluded: observational studies, retrospective studies, animal studies, reviews, and duplicate articles.

\section{Data extraction and outcome measures}

Potentially relevant studies were screened using Endnote X6 by two independent investigators (L.X. and W.-Z.L.) according to the prespecified criteria. The following data were extracted from the studies: authors, year of publication, group status (types and doses of antipsychotics and sample size), duration, blind evaluation, age of subjects, diagnoses, and outcome measures. Any disagreements were addressed by a discussion between the two investigators to reach a consensus. Otherwise, a third senior investigator (H.-Z.L.) was involved in the discussion as a final arbiter.

The main outcome measure of efficacy was the total score on the Positive and Negative Syndrome Scale (PANSS) (Kay et al. 1987) or the Brief Psychiatric Rating Scale (BPRS) (Overall and Gorham 1962). The secondary outcomes were the scores on the positive and negative symptom subscale of the PANSS or the Children's Psychiatric Rating Scale (CPRS) (Fish 1985). The main outcome measures of side effects included changes in weight and body mass index (BMI) and the incidence of various adverse events.

\section{Quality assessment}

The quality of each study was assessed using the Cochrane Risk of Bias (ROB) tool (Higgins and Julian 2008), including seven specific aspects, and the Jadad scale (Jadad et al. 1996) (high quality $\geq 3$ and low quality $<3$ ). The quality of the overall evidence was assessed using the Grades of Recommendation, Assessment, Development, and Evalua- tion (GRADE) (Guyatt et al. 2008). The overall level of each outcome was marked as "high," "moderate," "low," or "very low."

\section{Data synthesis and statistical analysis}

Different effect measures were chosen and analyzed using Review Manager Version 5.3 software according to the data type. We obtained the $95 \%$ confidence intervals (CIs) and drew forest maps to perform the data analysis. The mean difference (MD) was calculated for continuous data acquired using the same methods (e.g., weight and BMI). The standard MD (SMD) was calculated for continuous data acquired using different methods (e.g., scores of different scales). Risk ratios (RRs) with the $95 \% \mathrm{Cl}$ were calculated for dichotomous data (e.g., incidence of adverse events). Statistical differences were considered significant at $p<0.05$.

The study heterogeneity was estimated using $\mathrm{I}^{2}$ and chi-square test of homogeneity (Higgins et al. 2003). If $p>0.10$ and $i^{2}<50 \%$, which indicated homogeneity, a fixed-effect model was used. If $p \leq 0.10$ or $50 \% \leq \mathrm{I}^{2} \leq 75 \%$, which indicated significant heterogeneity, a randomeffect model was used. If $\mathrm{I}^{2}>75 \%$, we either conducted an exclusive sensitivity analysis or abandoned the meta-analysis.

\section{Results}

\section{Study characteristics}

The search initially identified 1649 potentially relevant studies. After removing duplicate records and screening according to the prespecified criteria, eight RCTs (Sikich et al. 2004, 2008; Huang et al. 2006; Mozes et al. 2006; Wei 2010; Liu and Yan 2015; Jiang and Gu 2016; Qi et al. 2016) were ultimately included (Fig. 1).

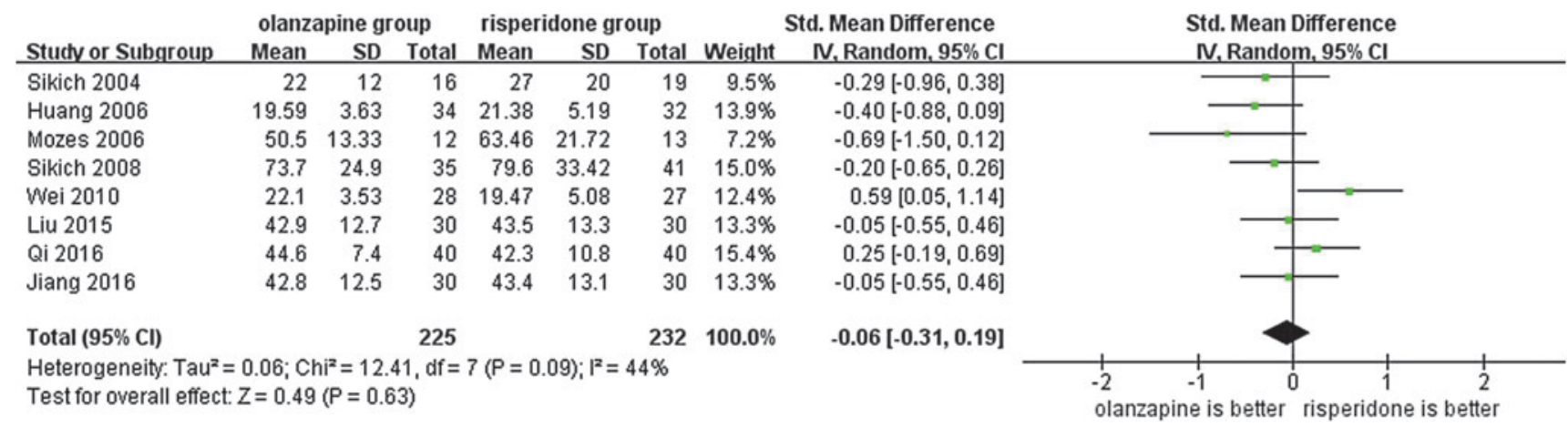

FIG. 2. Forest plot used to compare the total scores on the Positive and Negative Syndrome Scale or Brief Psychiatric Rating Scale between the olanzapine and risperidone groups in children and adolescents with psychosis. SD, standard deviation; CI, confidence interval. 


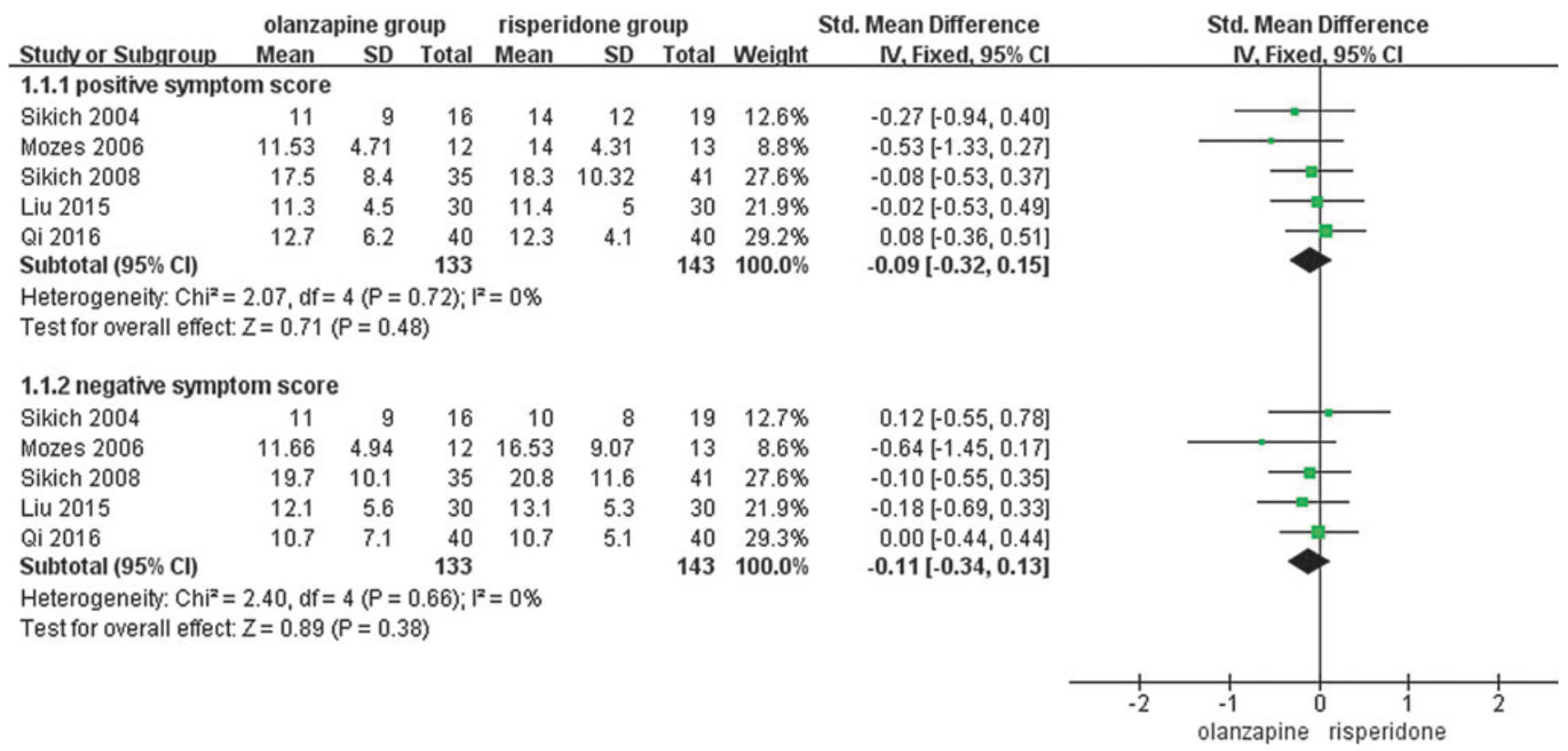

FIG. 3. Forest plot used to compare the subscale scores between the olanzapine and risperidone groups in children and adolescents with psychosis. SD, standard deviation; CI, confidence interval.

Three articles (Sikich et al. 2004, 2008; Mozes et al. 2006) were published in English and five articles (Huang et al. 2006; Wei 2010; Liu and Yan 2015; Jiang and Gu 2016; Qi et al. 2016) in Chinese. Since we systematically searched four main Chinese databases, five out of the eight studies meeting our screening criteria were from the Chinese-language literature.

Table 1 lists the eight RCTs, which involved 457 participants (sample size range, 25-80 patients). The mean trial duration was 8.5 weeks (range, $8-12$ weeks). Six studies included two groups, that is, olanzapine versus risperidone, and two studies included three groups. Among these studies, five studies were conducted in China $(n=321)$, two studies in the United States $(n=111)$, and one study in Israel $(n=25)$. Different scales were used to assess efficacy and safety in these studies.

The rates of clinical response in the groups per study are shown in Table 1. Five studies (Sikich et al. 2004, 2008; Huang et al. 2006; Mozes et al. 2006; Wei 2010) reported the rates and reasons of dropouts in details. The criteria used to determine clinical response varied across studies: CGI-I of " 1 " or " 2 " and reduction in the BPRS-C total score $\geq 20 \%$ (Sikich et al. 2004); CGI-I of " 1 " or " 2 " and reduction in the PANSS total score $\geq 20 \%$ (Sikich et al. 2008); reduction in the PANSS total score $\geq 50 \%$ and $\geq 30 \%$, respectively (Mozes et al. 2006); reduction in the BPRS total score $\geq 75 \%$ and $\geq 30 \%$, respectively ( Jiang and $\mathrm{Gu} 2016$ ); reduction in the PANSS total score $\geq 50 \%$ and $\geq 25 \%$, respectively (Liu and Yan 2015); and four grades of response assessments - cure, excellence, improvement, and failure (Huang et al. 2006; Wei 2010; Qi et al. 2016). When necessary, two formulae were used to calculate the rates of clinical response:

$$
\begin{aligned}
& \text { Rate }_{\text {excellence }}=\left(\mathrm{N}_{\text {cure }}+\mathrm{N}_{\text {excellence }}\right) / \mathrm{N}_{\text {total }} \times 100 \% \text {; } \\
& \text { Rate }_{\text {improvent }}=\left(\mathrm{N}_{\text {cure }}+\mathrm{N}_{\text {excellence }}+\mathrm{N}_{\text {improvent }}\right) / \mathrm{N}_{\text {total }} \times 100 \% \text {. }
\end{aligned}
$$

\section{$R O B$ and Jadad score}

The ROB in each study was assessed based on seven items (Table 2). Most items were considered "unclear risk" because of the lack of specific details regarding the research methods used in the studies. Only one RCT reported the method of allocation concealment, specifically stating that the medications were packaged in identical color-coded capsules, and two RCTs described a reasonable generation of a random sequence. In three non-Chinese RCTs, many participants dropped out (Discontinuation: $n \geq 20 \%$ ), and an intent-to-treat analysis was used for incomplete outcome data. Of these eight RCTs, two RCTs were double blind, three RCTs were open label, and two RCTs used a blind assessor. The

Table 3. Comparisons of Weight Changes and Body Mass Index Changes Between

\begin{tabular}{|c|c|c|c|c|c|c|}
\hline Index (change) & $\begin{array}{l}\text { No. of } \\
\text { studies }\end{array}$ & $\begin{array}{l}\text { Sample } \\
\text { size }\end{array}$ & $I^{2}$ & $\mathrm{p}$ & $\begin{array}{l}\text { Analytic } \\
\text { model }\end{array}$ & $\begin{array}{c}\text { Mean difference } \\
{[95 \% \mathrm{CI}]}\end{array}$ \\
\hline Weight & 4 & 211 & $62 \%$ & 0.05 & Random & $2.90[1.41,4.39]$ \\
\hline BMI & 2 & 111 & $0 \%$ & 1.00 & Fixed & $0.90[0.42,1.38]$ \\
\hline Cholesterol & 1 & 34 & Not applicable & - & Fixed & $30.10[12.57,47.63]$ \\
\hline Triglycerides & 1 & 33 & Not applicable & - & Fixed & $14.50[-25.10,54.10]$ \\
\hline Prolactin & 1 & 76 & Not applicable & - & Fixed & $-21.00[-30.39,-11.61]$ \\
\hline QTc & 1 & 76 & Not applicable & - & Fixed & $-10.70[0.09,21.31]$ \\
\hline
\end{tabular}
THE Olanzapine and RisPeridone Groups

Statistical differences are bold.

BMI, body mass index; QTc, QTc interval; CI, confidence interval. 
Table 4. Comparison of the Incidence of 33 Different Adverse Events Between The Olanzapine and RisPeridone Groups

\begin{tabular}{|c|c|c|c|c|c|c|}
\hline Adverse event (incidence) & $\begin{array}{l}\text { No. of } \\
\text { studies }\end{array}$ & Sample size & $I^{2}, \%$ & $\mathrm{p}$ & Analytic model & Risk ratio $[95 \% \mathrm{CI}]$ \\
\hline Excitement or agitation & 2 & 135 & 0 & 0.83 & fixed & $0.25[0.03,2.15]$ \\
\hline Hypersomnia & 5 & 276 & 0 & 0.71 & fixed & $1.98[1.15,3.43]$ \\
\hline Insomnia & 4 & 255 & 0 & 0.89 & fixed & $0.31[0.11,0.85]$ \\
\hline Abnormal liver function/enzymes & 3 & 201 & 41 & 0.03 & fixed & $1.71[0.66,4.42]$ \\
\hline Prolactin increase & 2 & 120 & 0 & 0.04 & fixed & $0.11[0.01,0.85]$ \\
\hline Granulopenia & 1 & 55 & - & - & not applicable & $0.19[0.01,3.85]$ \\
\hline Myotonia & 4 & 255 & 0 & 0.82 & fixed & $0.12[0.03,0.49]$ \\
\hline Tremors & 4 & 255 & 0 & 0.67 & fixed & $0.22[0.08,0.63]$ \\
\hline Torsional motion & 1 & 80 & - & - & not applicable & $0.14[0.01,2.68]$ \\
\hline Akathisia & 5 & 280 & 37 & 0.17 & fixed & $0.27[0.12,0.57]$ \\
\hline EPS & 2 & 91 & 89 & 0.003 & not applicable & $0.38[0.04,3.74]$ \\
\hline Dry mouth & 4 & 221 & 0 & 0.42 & fixed & $1.24[0.53,2.91]$ \\
\hline Blurred vision & 4 & 241 & 0 & 0.67 & fixed & $0.55[0.19,1.66]$ \\
\hline Constipation & 4 & 210 & 0 & 0.76 & fixed & $1.74[0.55,5.50]$ \\
\hline Increased salivation & 2 & 115 & 0 & 0.56 & fixed & $0.30[0.05,1.76]$ \\
\hline Nausea & 1 & 35 & - & - & not applicable & $0.17[0.01,3.03]$ \\
\hline Sudation & 1 & 80 & - & - & not applicable & $0.50[0.05,5.30]$ \\
\hline Dizziness & 4 & 236 & 0 & 0.49 & fixed & $1.41[0.45,4.41]$ \\
\hline Sychnosphygmia & 3 & 201 & 31 & 0.23 & fixed & $0.67[0.21,2.17]$ \\
\hline Arrhythmia & 2 & 120 & 20 & 0.26 & fixed & $0.71[0.15,3.50]$ \\
\hline Abnormal T-wave & 1 & 55 & - & - & not applicable & $3.12[0.30,32.03]$ \\
\hline Skin symptom & 2 & 90 & 0 & 0.95 & fixed & $0.18[0.02,1.43]$ \\
\hline Weight gain & 4 & 255 & 4 & 0.37 & fixed & $1.37[0.65,2.91]$ \\
\hline Anorexia & 1 & 55 & - & - & not applicable & $0.32[0.01,7.57]$ \\
\hline Headache & 3 & 155 & 0 & 0.90 & fixed & $0.79[0.27,2.30]$ \\
\hline Abnormal electroencephalogram, & 1 & 55 & - & - & not applicable & $0.96[0.06,14.65]$ \\
\hline urinary retention & 1 & 35 & - & - & not applicable & $3.53[0.15,81.11]$ \\
\hline Nervousness & 1 & 35 & - & - & not applicable & $2.38[0.24,23.84]$ \\
\hline Dysuria & 1 & 35 & - & - & not applicable & $3.53[0.15,81.11]$ \\
\hline Weakness & 1 & 35 & - & - & not applicable & $1.19[0.08,17.51]$ \\
\hline Irregular menses ${ }^{\mathrm{a}}$ & 1 & 13 & - & - & not applicable & $0.86[0.07,10.96]$ \\
\hline Musculoskeletal Pain & 1 & 35 & - & - & not applicable & $2.38[0.50,11.32]$ \\
\hline Decreased coordination & 1 & 35 & - & - & not applicable & $3.53[0.15,81.11]$ \\
\hline
\end{tabular}

Statistical differences are bold.

The sample size of this item included the number of females only.

EPS, extrapyramidal symptoms.

mean Jadad score of the eight RCTs was 2.9 (range, 1-6) and the high-quality RCTs accounted for $37.5 \%$ (3/8 RCTs).

\section{Efficacy}

Since the outcome measure of efficacy was assessed using different scales (PANSS: three RCTs; BPRS: three RCTs; and both: two RCTs), the SMD was used in the meta-analysis. The $\mathrm{I}^{2}$-value was acceptable. However, the corresponding $p$-value was too small $\left(\mathrm{I}^{2}=38 \%, p=0.05\right)$. Hence, we used a random-effect model. The results of the meta-analysis showed no significant differences in the total scores on the PANSS or BPRS between the two groups ( $\mathrm{SMD}=-0.06$, $95 \% \mathrm{CI}=[-0.31,0.19], p=0.63$ ) (Fig. 2). Furthermore, a sensitivity analysis was performed after excluding Wei's study as an outlier. The $\mathrm{I}^{2}$ value was reduced to $5 \%\left(\mathrm{I}^{2}=5 \%, p=0.39\right)$ and there was still no statistical difference in total score between olanzapine and risperidone groups $(\mathrm{SMD}=-0.13,95 \% \mathrm{CI}=[-0.33,0.06], p=0.19)$.

The positive and negative symptom scores of the 276 patients in 5 RCTs (Sikich et al. 2004, 2008; Mozes et al. 2006; Liu and Yan 2015; Qi et al. 2016) were compared using the SMD (CPRS: 1 RCTs and PANSS: 4 RCTs). Figure 3 presents the homogeneity in both the positive $(p=0.72, \mathrm{I} 2=0 \%)$ and negative $(p=0.66, \mathrm{I} 2=0 \%)$ symptom scores. Therefore, a fixed-effect model was used. No significant dif- ference was observed in either the positive symptom score (SMD = $-0.09,95 \% \mathrm{CI}=[-0.32,0.15], p=0.48)$ or the negative symptom score $(\mathrm{SMD}=-0.11,95 \% \mathrm{CI}=[-0.34,0.13], p=0.38)$ between the two groups. According to the criteria of the GRADE approach, the quality of the evidence of the outcome measures of the total, positive, and negative symptom scores was rated as "moderate."

\section{Adverse side effects}

The adverse side effects were reported in all eight RCTs (Table 1), five (Huang et al. 2006; Wei 2010; Liu and Yan 2015; Jiang and Gu 2016; Qi et al. 2016) of which used the Treatment Emergent Symptoms Scale (TESS) (Zhang 1998). The changes in weight $(\mathrm{MD}=2.90,95 \% \mathrm{CI}=[1.41,4.39], p=0.0001, \mathrm{~kg})$ and $\mathrm{BMI}$ $\left(\mathrm{MD}=0.90,95 \% \mathrm{CI}=[0.42,1.38], p=0.0003, \mathrm{~kg} / \mathrm{m}^{2}\right)$ were significantly higher in the olanzapine group than those in the risperidone group (Table 3). The quality of the evidence was rated as "moderate" according to the GRADE criteria.

Table 4 displays a comparison of the incidence of 33 different adverse events between the olanzapine and risperidone groups. The $\mathrm{RR}$ is shown for each item, and a fixed-effect model was used. The incidence of hypersomnia/sedation $(\mathrm{RR}=1.98,95 \% \mathrm{CI}=[1.15$, 3.43], $p=0.01$ ) was higher in the olanzapine group, while the 
incidence of insomnia $(\mathrm{RR}=0.31,95 \% \mathrm{CI}=[0.11,0.85], p=0.02)$, prolactin elevation $(\mathrm{RR}=0.11,95 \% \mathrm{CI}=[0.01,0.85], p=0.03)$, myotonia $(\mathrm{RR}=0.12,95 \% \mathrm{CI}=[0.03,0.49], p=0.003)$, tremor $(\mathrm{RR}=0.22,95 \% \mathrm{CI}=[0.08,0.63], \quad p=0.005), \quad$ or akathisia $(\mathrm{RR}=0.27,95 \% \mathrm{CI}=[0.12,0.57], p=0.0007)$ was higher in the risperidone group. The quality of this evidence was rated as "low."

\section{Discussion}

\section{Main findings}

This meta-analysis of 8 RCTs involving 457 participants found no significant differences in the mean score on the PANSS/BPRS or in the positive or negative symptom scores between the olanzapine and risperidone groups. Based on the GRADE criteria, the quality of this evidence was "moderate." Altogether, there is no difference in efficacy between olanzapine and risperidone for the treatment of children and adolescents with psychosis. However, it is worthy of mention that it is hard to interpret the study results without evaluating the "adequacy" of the included trials. From the literature, we did not know whether they all reached therapeutic doses (chlorpromazine equivalent) and sustained these therapeutic doses for sufficient duration, and whether those doses were maximal efficacy (which can exceed $30 \mathrm{mg}$ for olanzapine). Thus, this conclusion that risperidone and olanzapine are equivalent in efficacy may be statistically accurate; however, Figure 2 suggests a clear trend toward olanzapine superiority for total PANSS and BPRS scores. Taken together, whether the clinical efficacy of olanzapine for the treatment of children and adolescents with psychosis is equivalent or superior to risperidone will need to be confirmed in the new and large sample size of clinical trials in future investigation before a firm conclusion could be drawn.

Regarding the adverse side effects, the changes in weight and BMI were significantly higher in the olanzapine group than in the risperidone group. These results are consistent with those reported in a previous meta-analysis of 14 RCTs, which showed that olanzapine was associated with the greatest weight increase, aripiprazole with the lowest weight increase, and risperidone in between (Almandil et al. 2013). In addition, there were significant differences in the incidence of hypersomnia/sedation, insomnia, prolactin elevation, myotonia, tremor, and akathisia between the two groups. In summary, olanzapine has a greater impact on body weight and BMI, while risperidone displays more side effects in the areas of myotonia, tremor, akathisia, and other EPS.

Olanzapine and risperidone, which are similar to other SGAs, exert their antipsychotic effect by blocking dopamine $\mathrm{D}_{2}$ and serotonin $5-\mathrm{HT}_{2 \mathrm{~A}}$ receptors (Mauri et al. 2014). Certain pharmacological mechanisms can explain the similarity in their efficacy and the difference in their side effects (Buckley 2007). First, targeted dopaminergic blockade occurs in different locations within the brain. EPS result from dopamine antagonism in the forebrain basal nuclei, and elevated prolactin results from the inhibition of the $D_{2}$ receptor in the anterior pituitary gonadotropic cells. Second, $\mathrm{D}_{2}$ receptor occupancy can predict different reactions to the drugs, such as a clinical response $(\geq 65 \%)$, elevated prolactin $(\sim 72 \%)$, and EPS $(>78 \%)$. Although SGAs achieve the level of binding required for efficacy, only some SGAs, such as risperidone and not olanzapine, achieve the high level of binding that results in side effects. In addition, olanzapine has a strong binding affinity to histamine $\mathrm{H}_{1}$ and muscarinic acetylcholine $\mathrm{M}$ receptors. Thus, olanzapine has a considerable sedative effect (Miller 2004). Its anticholinergic activity may be an additional factor that explains the low incidence of EPS (Hyde and Crook 2001). The mechanism of weight gain induced by SGAs has not been identified to date, but is likely asso- ciated with activity that occurs at several different receptors (i.e., $\mathrm{H}_{1}, 5-\mathrm{HT}_{2 \mathrm{~A}}, 5-\mathrm{HT}_{2 \mathrm{C}}, \mathrm{M}_{3}$, and adrenergic receptors). Currently, more attention is focused on the $\mathrm{H}_{1}$ receptor (Roerig et al. 2011). Due to the widespread interpersonal variation in the sensitivity to antipsychotics, there are no drugs or fixed doses that can achieve a clinical response without any side effects. Further studies that specifically target the pediatric population are needed. Moreover, the rates of response for both SGAs are generally $<50 \%$ in children and adolescents, with some side effects. Thus, we should individualize the drug choice and dosage regimen for the treatment of these pediatric patients. However, it is noteworthy that the $\mathrm{D}_{2}$ receptor occupancy argument for efficacy and adverse effects is complicated. The presence of EPS and neuroleptic malignant syndrome with antipsychotics is prima facie evidence that all of them are capable of occupying sufficient $\mathrm{D}_{2}$ receptors to induce side effects. Disparate results have been generated based on species (humans, monkeys, and rats), imaging modality (PET vs. SPECT), and dosing. Functional features such as intrinsic efficacy likely play a substantial role in efficacy and adverse effects, independent of receptor occupancy (Iyo et al. 2013; Marazziti et al. 2016).

\section{Limitations}

There are several limitations to our study. First, few RCTs evaluating the use of SGAs in children or adolescents were found, and most studies involving adults were removed during the screening process. The use of antipsychotics in the pediatric population remains controversial, and conditions are difficult to control in clinical trials. Second, the overall quality of the studies included was low. Most studies did not provide specific details about their research methods. In particular, in the Chinese RCTs, the generation of a random sequence and allocation concealment were questionable. In addition, many participants dropped out in the non-Chinese RCTs, which may be related to this clinical situation in which Chinese patients are hospitalized for a longer period of time than others. Third, we could not collect data regarding the effects of therapeutic doses and treatment duration due to inadequate information. Finally, children and adolescents with psychosis need a full-course therapy, and we cannot assess the medium and long-term prognoses based on trials that lasted only a few weeks. These limitations reduce the credibility of our conclusions.

\section{Clinical Significance}

The results of this meta-analysis indicate that olanzapine and risperidone are not significantly different in their efficacy in the treatment of children and adolescents with psychosis, but the side effect profiles of the two medications differ. These findings have implications for the selection of antipsychotic drugs in clinical practice. However, this is a preliminary study with several limitations. Also, selecting more reasonable treatment plans according to the patients' specific situations and designing more rational studies with larger sample sizes, particularly involving children and adolescents, are necessary.

\section{Acknowledgment}

We thank Professor Chun-Bo Li for guidance and suggestions.

\section{Disclosure}

No competing financial interests exist.

\section{References}

Almandil NB, Liu Y, Murray ML, Besag FMC, Aitchison KJ, Wong ICK: Weight gain and other metabolic adverse effects associated with 
atypical antipsychotic treatment of children and adolescents: A systematic review and meta-analysis. Pediatric Drugs 15:139-150, 2013.

Arango C, Diaz-Caneja CM, Pina-Camacho L, Fraguas D: Are children treated with second-generation antipsychotics at higher risk of weight gain than adults? Neuropsychopharmacology 41:S338-S339, 2016.

Baeza I, Vigo L, de la Serna E, Calvo-Escalona R, Merchán-Naranjo J, Rodríguez-Latorre P, ... Castro-Fornieles J: The effects of antipsychotics on weight gain, weight-related hormones and homocysteine in children and adolescents: A 1-year follow-up study. Eur Child Adolesc Psychiatry 26:35-46, 2017.

Buckley PF. Receptor-binding profiles of antipsychotics: Clinical strategies when switching between agents. J Clin Psychiatry 68 Suppl 6:5-9, 2007.

Correll CU, Kane JM: One-year incidence rates of tardive dyskinesia in children and adolescents treated with second-generation antipsychotics: A systematic review. J Child Adolesc Psychopharmacol 17:647-656, 2007.

Correll CU, Penzner JB, Parikh UH, Mughal T, Javed T, Carbon M, Malhotra AK: Recognizing and monitoring adverse events of second-generation antipsychotics in children and adolescents. Child Adolesc Psychiatr Clin N Am 15:177-206, 2006.

Fish B: Children's psychiatric rating scale. Psychopharmacol Bull 753-770, 1985.

García M, Ilzarbe D, Mansilla S, Pérez A, Fábrega M, Parellada E,... Baeza I: First episode psychosis during adolescence: Clinical and therapeutic differences from adulthood onset. Eur Neuropsychopharmacol 23:S592-S593, 2013.

Guyatt GH, Oxman AD, Vist GE, Kunz R, Falck-Ytter Y, Alonso-Coello P, Schunemann HJ: GRADE: An emerging consensus on rating quality of evidence and strength of recommendations. BMJ 336:924-926, 2008.

Harvey RC, James AC, Shields GE: A systematic review and network meta-analysis to assess the relative efficacy of antipsychotics for the treatment of positive and negative symptoms in early-onset schizophrenia. CNS Drugs 30:27-39, 2016.

Higgins JPT: Cochrane Handbook for Systematic Reviews of Interventions. Hoboken, NJ, John Wiley \& Sons, 2008.

Higgins JPT, Thompson SG, Deeks JJ, Altman DG: Measuring inconsistency in meta-analyses. BMJ 327:557-560, 2003.

Huang X, Zhu H, Mai G: The clinical study of olanzapine verse risperidone in treatment of first-episode childhood adolescent schizophrenia [in Chinese]. Guangdong Med J 27:270-272, 2006.

Hyde TM, Crook JM: Cholinergic systems and schizophrenia: Primary pathology or epiphenomena? J Chem Neuroanat 22:53-63, 2001.

Iyo M, Tadokoro S, Kanahara N, Hashimoto T, Niitsu T, Watanabe H, Hashimoto K: Optimal extent of dopamine D2 receptor occupancy by antipsychotics for treatment of dopamine supersensitivity psychosis and late-onset psychosis. J Clin Psychopharmacol 33:398-404, 2013.

Jadad AR, Moore RA, Carroll D, Jenkinson C, Reynolds DJM, Gavaghan DJ, Mcquay HJ: Assessing the quality of reports of randomized clinical trials: Is blinding necessary? Control Clin Trials 17:1-12, 1996.

Jiang L, Gu GZ: Analysis of efficacy and tolerability of olanzapine in treatment of schizophrenia in children [in Chinese]. Chin J Modern Drug Appl 10:92-93, 2016.

Kay SR, Fiszbein A, Opler LA: The Positive and Negative Syndrome Scale (PANSS) for Schizophrenia. Schizophr Bull 13:261, 1987.

Kumar A, Datta SS, Wright SD, Furtado VA, Russell PS: Atypical antipsychotics for psychosis in adolescents. Cochrane Database Syst Rev CD009582, 2013.

Liu XF, Yan FJ: A comparative study of olanzapine and risperidone in the treatment of Children with first-episode schizophrenia [in Chinese]. Chin Pediatr Integr Tradit West Med 7:79-80, 2015.

Marazziti D, Piccinni A, Baroni S, Mungai F, Presta S, Mucci F, Dell'Osso L: Current trends on antipsychotics: Focus on asenapine. Curr Med Chem 23:2204-2216, 2016.
Mauri MC, Paletta S, Maffini M, Colasanti A, Dragogna F, Di Pace C, Altamura AC: Clinical pharmacology of atypical antipsychotics: An update. EXCLI J 13:1163-1191, 2014.

Miller DD. A typical antipsychotics: Sleep, sedation, and efficacy. Prim Care Companion J Clin Psychiatry 6(Suppl 2):3-7, 2004.

Mozes T, Ebert T, Michal SE, Spivak B, Weizman A: An open-label randomized comparison of olanzapine versus risperidone in the treatment of childhood-onset schizophrenia. J Child Adolesc Psychopharmacol 16:393-403, 2006.

Overall JE, Gorham DR: The brief psychiatric rating scale. Psychol Rep 10:799-812, 1962.

Qi QW, Luo YL, Jiang YM, Lu YZ: The analysis of clinical efficacy and safety of olanzapine in the treatment of child and adolescents schizophrenia [in Chinese]. J Int Psychiatry 269-271, 2016.

Remschmidt H, Martin M, Fleischhaker C, Theisen FM, Hennighausen K, Gutenbrunner C, Schulz E: Forty-two-years later: The outcome of childhood-onset schizophrenia. J Neural Transm 114:505-512, 2007.

Roerig JL, Steffen KJ, Mitchell JE: Atypical antipsychotic-induced weight gain: Insights into mechanisms of action. CNS Drugs 25: 1035-1059, 2011.

Ropcke B, Eggers C: Early-onset schizophrenia: A 15-year followup. Eur Child Adolesc Psychiatry 14:341-350, 2005.

Seida JC, Schouten JR, Mousavi SS, Hamm M, Beaith A, Vandermeer B, Dryden DM, Boylan K, Newton AS, Carrey N: First- and second-generation antipsychotics for children and young adults. Comp Effectiv Rev 39, 2012.

Sikich L, Frazier JA, McClellan J, Findling RL, Vitiello B, Ritz L, Ambler D, Puglia M, Maloney AE, Michael E, De Jong S, Slifka K, Noyes N, Hlastala S, Pierson L, McNamara NK, DelportoBedoya D, Anderson R, Hamer RM, Lieberman JA: Double-blind comparison of first- and second-generation antipsychotics in earlyonset schizophrenia and schizoaffective disorder: Findings from the treatment of early-onset schizophrenia spectrum disorders (TEOSS) study. Am J Psychiatry 165:1420-1431, 2008.

Sikich L, Hamer RM, Bashford RA, Sheitman BB, Lieberman JA: A pilot study of risperidone, olanzapine, and haloperidol in psychotic youth: A double-blind, randomized, 8-week trial. Neuropsychopharmacology 29:133-145, 2004.

Wei SZ. A comparative study in 60 cases of olanzapine and risperidone in the treatment of adolescents with first-episode schizophrenia [in Chinese]. Med J Chin People Health 22:1414-1415, 2010.

Yan JJ, Cui YH. An analysis of psychiatric medications in children and adolescents with schizophrenia of Beijing Anding Hospital from 2010 to 2015 [in Chinese]. J Psychiatry 29:410-413, 2016.

Zhang MY. Psychiatric Rating Scale Manual [in Chinese]. Hunan, Hunan Science and Technology Press, 1998.

Address correspondence to: Huan-Zhong Liu, MD, PHD Department of Psychiatry Chaohu Hospital of Anhui Medical University 64 Chaohu North Road Hefei 238000

Anhui

China

E-mail: huanzhongliu@126.com

Xiang-Yang Zhang, MD, PHD

Department of Psychiatry and Behavioral Sciences

The University of Texas Health Science Center at Houston 1954 East Road

Houston, TX 77054

E-mail: xiang.y.zhang@uth.tmc.edu 